\title{
MUTU PELAYANAN KESEHATAN TERHADAP KEPUASAN PASIEN DI PUSAT KESEHATAN ANGKATAN DARAT (PUSKESAD) POLKES KABUPATEN TAKALAR
}

\author{
Ali Imran, Andi Alim Bagu, Yuliana Baharuddin \\ Fakultas Kesehatan Masyarakat UPRI Makassar
}

\begin{abstract}
The quality of health services is one of main focus for community. Awareness of the quality of health services is increasing with the demand for improving the quality from service providers and community as a service user. The quality of health services greatly affects patient satisfaction. The design of this study is analytic survey research with cross sectional approach. The purpose of this study is to know the relation of quality of health service to patient satisfaction at Army Health Center (PUSKESAD) POLKES of Takalar Regency in 2017. The research is conducted at Army Health Center (PUSKESAD) POLKES Takalar District. The sample in this study are patients who treated at the Army Health Center (PUSKESAD) POLKES Takalar District in June of 2017 as many as 94 people using a simple random sampling technique. Data analysis in this research is univariate and bivariate analysis using chi square test. The results showed that there was a significant correlation between health service quality based on indicator physical appearance, reliability, responsiveness, assurance, and empathy with patient satisfaction with each $\mathrm{p}$ value $=0,000$. It is hoped that the Army Health Center (PUSKESAD) POLKES can improve the quality of health services and the confidence of patients in utilizing health services more increase.
\end{abstract}

Keywords: Quality of service, satisfaction, patient

\section{PENDAHULUAN}

Kepuasan pasien merupakan komparasi antara harapan dan hal-hal yang telah diperoleh pasien dari hasil kinerja pelayanan di suatu institusi kesehatan. Hasil dari kepuasan pasien tersebut dapat menunjukkan mutu/kualitas pelayanan kesehatan yang telah berjalan. Menurut undang-undang No. 44 tahun 2009, institusi pelayanan kesehatan yang menyelenggarakan pelayanan kesehatan perorangan secara paripurna yang menyediakan pelayanan rawat inap, rawat jalan, dan gawat darurat harus mampu memberikan pelayanan kesehatan secara kuratif maupun preventif serta menyelenggarakan pelayanan rawat jalan dan rawat inap (Grace, 2017).

Mutu pelayanan kesehatan merupakan fokus utama bagi masyarakat saat ini. Kesadaran dan kepedulian terhadap mutu memang semakin meningkat. Tuntutan akan peningkatan mutu pelayanan kesehatan sering didengungkan baik dari pihak penyedia jasa pelayanan maupun dari pihak masyarakat sebagai pemakai jasa pelayanan. Mutu pelayanan kesehatan yang disusun oleh Institute of Madicine (IOM) menyebutkan mutu pelayanan kesehatan adalah suatu langkah kearah peningkatan pelayanan kesehatan baik individu, maupun populasi sesuai dengan keluaran (outcome) kesehatan yang diharapkan dan sesuai dengan pengetahuan profesional terkini (Hatta, 2008). Penyelenggaraan upaya kesehatan yang bermutu harus lebih mengutamakan pendekatan, pemeliharaan, peningkatan kesehatan dan pencegahan penyakit dilaksanakan secara profesional dan memberikan manfaat bagi peningkatan derajat kesehatan masyarakat, sehingga setiap tenaga kesehatan perlu mempunyai moralitas yang tinggi, berbudi luhur, memegang teguh etika profesi, harus mampu membangkitkan dan mendorong peran serta masyarakat dalam memberi pelayanan tanpa memandang perbedaan suku, golongan, agama dan status ekonomi sosialnya (Sukesih, 2012).

Mutu pelayanan kesehatan menjadi hal yang penting dalam organisasi pelayanan. Adanya kepuasan pasien terhadap rumah sakit menentukan keberadaan rumah sakit dalam jangka panjang. Kepercayaan pelanggan terhadap rumah sakit dapat tercipta dengan terpenuhinya kebutuhan dan kepuasan terhadap pelayanan yang diberikan rumah sakit. Pasien yang puas merupakan aset yang sangat berharga karena apabila pasien puas, maka akan terus melakukan pemakaian terhadap jasa pilihannya, 
tetapi jika pasien merasa tidak puas, maka akan membentuk persepsi yang kurang baik kepada orang lain tentang pengalaman buruknya (Grace, 2017). Tujuan dalam penelitian ini adalah untuk mengetahui hubungan mutu pelayanan pasien berdasarkan indikator pelayanan (penampilan fisik, kehandalan, ketanggapan, jaminan, dan empati) dengan kepuasan pasien di Pusat Kesehatan Angkatan Darat (PUSKESAD) POLKES Kabupaten Takalar tahun 2017.

\section{METODE PENELITIAN}

\section{Jenis Penelitian}

Jenis penelitian ini adalah penelitian survei analitik dengan pendekatan cross sectional untuk mengetahui hubungan mutu pelayanan dengan kepuasan pasien di di Pusat Kesehatan Angkatan Darat (PUSKESAD) POLKES Kabupaten Takalar tahun 2017.

\section{Waktu dan Lokasi Penelitian}

Penelitian dilaksanakan pada bulan Juni - Juli tahun 2017 di Pusat Kesehatan Angkatan Darat (PUSKESAD) POLKES Kabupaten Takalar.

\section{Populasi dan Sampel}

Populasi dalam penelitian ini adalah semua pasien yang berobat di Pusat Kesehatan Angkatan Darat (PUSKESAD). Adapun cara pengambilan sampel dengan teknik simple random sampling atau sampel acak sederhana dengan jumlah 94.

\section{Teknik Pengumpulan Data}

Pengumpulan data dalam penelitian ini dilakukan dengan menggunakan data primer yaitu melalui wawancara langsung kepada responden dengan menggunakan kuesioner yang berisi pertanyaan tentang indikator pelayanan berdasarkan penampilan fisik, kehandalan, ketanggapan, jaminan, dan empati adalah menggunkan kuesioner dan data sekunder diperoleh dari Pusat Kesehatan Angkatan Darat (PUSKESAD) POLKES Kabupaten Takalar.

\section{Analisa Data}

Analisis data dalam penelitian ini menggunakan uji chi square, yaitu menguji hubungan variabel mutu pelayanan dengan kepuasan pasien. Kemudian data yang telah diolah disajikan dalam bentuk tabel disertai dengan penjelasan.

\section{HASIL DAN PEMBAHASAN}

\section{Analisis Univariat}

Karakteristik responden berdasarkan hasil penelitian yang telah dilakukan dalam dilihat pada tabel di bawah ini:

\section{Tabel 1. Distribusi Responden berdasarkan Kelompok Umur di Pusat Kesehatan Angkatan Darat (PUSKESAD) POLKES Kabupaten Takalar}

\begin{tabular}{lcc}
\hline Variabel Penelitian & n & \% \\
\hline Kategori Umur Responden & & \\
$20-25$ tahun & 13 & 13,8 \\
$26-30$ tahun & 24 & 25,5 \\
$31-35$ tahun & 6 & 6,4 \\
$36-40$ tahun & 6 & 6,4 \\
$41-45$ tahun & 12 & 12,8 \\
> 46 tahun & 33 & 35,1 \\
Jumlah & 94 & 100,0 \\
Jenis Kelamin & & \\
Laki-laki & 44 & 46,8 \\
Perempuan & 50 & 53,2 \\
Jumlah & 94 & 100,0 \\
\hline
\end{tabular}

Tabel. 1 menunjukkan bahwa dari 94 responden diperoleh kelompok umur terbanyak pada kelompok umur > 46 tahun yaitu sebanyak 33 orang $(35,1 \%)$ dan kelompok umur terendah pada kelompok umur $31-35$ tahun serta $36-40$ tahun sebanyak 6 orang $(6,4$ 
\%). Dari 94 responden, jenis kelamin tertinggi adalah pada jenis kelamin perempuan sebanyak 50 orang $(53,2 \%)$ dan jenis kelamin terendah pada jenis kelamin laki - laki sebanyak 44 orang $(46,8 \%)$

\section{Analisis Bivariat}

Berdasarkan tabel. 2 menunjukkan hasil uji statistik dengan menggunakan uji chi square test diperoleh nilai $\mathrm{p}=0,000$. Karena nilai $<0,05$ (nilai value $<$ ), ini berarti ada hubungan antara penampilan fisik dengan kepuasan pasien rawat jalan. Hasil menunjukkan bahwa dari 94 responden yang menyatakan cukup terhadap penampilan fisik sebanyak $65(69,1 \%)$ dan yang menyatakan kurang sebanyak 29 (30,9\%). Kemudian dari hasil tabulasi silang menunjukkan bahwa dari 65 responden yang menyatakan penampilan fisik terdapat 57 $(87,7 \%)$ yang menilai cukup terhadap kepuasan pasien rawat jalan. Sedangkan dari 29 responden yang menyatakan kurang terhadap penampilan fisik terdapat $15(51,7 \%)$ yang menilai kurang terhadap kepuasan pasien rawat jalan. Hasil uji statistik menunjukkan bahwa ada hubungan antara penampilan fisik dengan kepuasan pasien.

Bukti langsung (tampilan fisik) biasanya digunakan untuk menaikkan image di mata konsumen yang dapat digambarkan dengan kebersihan ruangan, kerapihan berpakaian, dan penataan tempat. Pada rumah sakit, faktor kondisi fisik pada umumnya akan memberikan gambaran bagaimana rumah sakit tersebut dapat berpotensi untuk menunjukkan fungsinya sebagai tempat pelayanan kesehatan (Grace, 2017). Menurut penelitian Muhyi (2016) menyatakan bahwa kenyamanan ruang tunggu adalah salah satu faktor yang berhubungan dengan kepuasan pasien.

Tabel 2. Hubungan Penampilan Fisik, Kehandalan, Ketanggapan, Jaminan dan Empati dengan Kepuasan Pasien di Pusat Kesehatan Angkatan Darat (PUSKESAD) POLKES Kabupaten Takalar

\begin{tabular}{|c|c|c|c|c|c|c|c|}
\hline \multirow{3}{*}{ Variabel Penelitian } & \multicolumn{4}{|c|}{ Kepuasan Pasien } & \multicolumn{2}{|c|}{ Total } & \multirow{3}{*}{$\mathbf{P}$} \\
\hline & \multicolumn{2}{|c|}{ Cukup } & \multicolumn{2}{|c|}{ Kurang } & \multirow{2}{*}{$\mathbf{n}$} & \multirow{2}{*}{$\%$} & \\
\hline & $\mathrm{n}$ & $\%$ & $\mathrm{n}$ & $\%$ & & & \\
\hline \multicolumn{8}{|l|}{ Penampilan Fisik } \\
\hline Cukup & 57 & 87,7 & 8 & 12,3 & 65 & 100 & \multirow{3}{*}{0,00} \\
\hline Kurang & 14 & 48,3 & 15 & 51,7 & 29 & 100 & \\
\hline Jumlah & 71 & 75,5 & 23 & 24,5 & 94 & 100 & \\
\hline \multicolumn{8}{|l|}{ Kehandalan } \\
\hline Cukup & 56 & 87,5 & 8 & 12,3 & 64 & 100 & \multirow{3}{*}{0,000} \\
\hline Kurang & 15 & 50,0 & 15 & 50,0 & 30 & 100 & \\
\hline Jumlah & 71 & 75,5 & 23 & 24,5 & 94 & 100 & \\
\hline \multicolumn{8}{|l|}{ Ketanggapan } \\
\hline Cukup & 53 & 93,0 & 4 & 7,0 & 57 & 100 & \multirow{3}{*}{0,000} \\
\hline Kurang & 18 & 48,6 & 19 & 51,4 & 37 & 100 & \\
\hline Jumlah & 71 & 75,5 & 23 & 24,5 & 94 & 100 & \\
\hline \multicolumn{8}{|l|}{ Jaminan } \\
\hline Cukup & 60 & 87,0 & 9 & 13,0 & 69 & 100 & \multirow{3}{*}{0,000} \\
\hline Kurang & 11 & 44,0 & 14 & 56,0 & 25 & 100 & \\
\hline Jumlah & 71 & 75,5 & 23 & 24,5 & 94 & 100 & \\
\hline \multicolumn{8}{|l|}{ Empati } \\
\hline Cukup & 45 & 88,2 & 6 & 11,8 & 51 & 100 & \multirow{3}{*}{0,004} \\
\hline Kurang & 26 & 60,5 & 17 & 39,5 & 43 & 100 & \\
\hline Jumlah & 71 & 75,5 & 23 & 24,5 & 94 & 100 & \\
\hline
\end{tabular}

Sumber : Data Primer

Berdasarkan tabel. 2 menunjukkan hasil uji statistik dengan menggunakan uji chi square test diperoleh nilai $\mathrm{p}=0,000$. Karena nilai < 0,05 (nilai value $<$ ), ini berarti ada hubungan 
antara kehandalan dengan kepuasan pasien rawat jalan. Dari 94 responden, yang menyatakan cukup terhadap kehandalan sebanyak $64(68,1 \%)$ dan yang menyatakan kurang sebanyak 30 (31,9\%). Kemudian dari hasil tabulasi silang pada tabel 4 menunjukkan bahwa dari 64 responden yang menyatakan kehandalan terdapat $56(87,5 \%)$ yang menilai cukup terhadap kepuasan pasien. Sedangkan dari 30 responden yang menyatakan kurang terhadap kehandalan terdapat $15(50,5 \%)$ yang menilai kurang terhadap kepuasan pasien. Menurut Semiaji Santoso (2012) dalam Grace (2017) , kehandalan meruapakan salah satu sikap kualitas yang memiliki hubungan erat dengan kepuasan pelanggan. Kehandalan adalah penilaian responden terhadap kehandalan dari petugas untuk memberikan pelayanan yang dijanjikan benar, seperti kemampuan dokter dalam mendiagnosa penyakit, petugas setiap hari melakukan pemeriksaan pada pasien, pemberian obat atau suntik dengan jadwal yang ditentukan (Tokalese dkk, 2015). Hasil penelitian ini sejalan dengan peneitian yang dilakukan oleh Vania (2017) bahwa ada hunbungan antara kehandalan dengan kepuasan pasien pada ruang rawat inap RSIA Kasih Ibu Manado.

Hasil uji statistik dengan menggunakan uji chi square test diperoleh nilai $\mathrm{p}=0,000$. Karena nilai $<0,05$ (nilai value $<$ ), ini berarti ada hubungan antara ketanggapan dengan kepuasan pasien rawat jalan. Dari 94 responden, yang menyatakan cukup terhadap ketanggapan sebanyak $57(60,6 \%)$ dan yang menyatakan kurang sebanyak $37 \quad(39,4 \%)$. Kemudian dari hasil tabulasi silang pada table 5 menunjukkan bahwa dari 57 responden yang menyatakan ketanggapan terdapat $53(93,0 \%)$ yang menilai cukup terhadap ketanggapan pasien. Sedangkan dari 37 responden yang menyatakan kurang terhadap ketanggapan terdapat $19(51,4 \%)$ yang menilai kurang terhadap kepuasan pasien. Hasil uji statistik menunjukkan bahwa ada hubungan antara ketanggapan dengan kepuasan pasien. Penyedia jasa pelayanan harus mempunyai kemampuan dalam menanggapi setiap keluhan pasien. Dengan demikian, daya tanggap yang tinggi dari pihak pemberi jasa pelayanan akan memberikan rasa kepercayaan pada pasien bahwa mereka akan selalu tertolong. Hasil penelitian ini sejalan dengan penelitian Vania dkk (2017) di RSIA Kasih Ibu Manado bahwa ada hubungan antara dimensi daya tanggap dengan kepuasan pasien.

Hasil uji statistik dengan menggunakan uji chi square test diperoleh nilai $\mathrm{p}=0,000$. Karena nilai $<0,05$ (nilai value $<$ ), ini berarti ada hubungan antara jaminan dengan kepuasan pasien rawat jalan. Dari 94 responden, yang menyatakan cukup terhadap jaminan sebanyak $69(73,4 \%)$ dan yang menyatakan kurang sebanyak 25 (26,6\%). Kemudian dari hasil tabulasi silang menunjukkan bahwa dari 69 responden yang menyatakan jaminan terdapat $60(87,0 \%)$ yang menilai cukup terhadap jaminan pasien rawat jalan. Sedangkan dari 25 responden yang menyatakan kurang terhadap jaminan terdapat $14(56,0 \%)$ yang menilai kurang terhadap kepuasan pasien. Jaminan mencakup kemampuan, kesopanan dan sifat dapat dipercaya yang dimiliki oleh staf, bebas dari bahaya atau resiko keragu-raguan, perilaku para karyawan diharapkan dapat menumbuhkan rasa aman bagi pelanggannya (Grace, 2017).

Hasil uji statistik dengan menggunakan uji chi square test diperoleh nilai $\mathrm{p}=0,004$. Karena nilai $<0,05$ (nilai value $<$ ), ini berarti ada hubungan antara empati dengan kepuasan pasien rawat jalan. Dari 94 responden, yang menyatakan cukup terhadap empati sebanyak $51(54,3 \%)$ dan yang menyatakan kurang sebanyak $43(45,7 \%)$. Kemudian dari hasil tabulasi silang menunjukkan bahwa dari 51 responden yang menyatakan empati terdapat 45 $(88,2 \%)$ yang menilai cukup terhadap empati pasien. Sedangkan dari 43 responden yang menyatakan kurang terhadap empati terdapat 17 $(39,5 \%)$ yang menilai kurang terhadap kepuasan pasien. Hasil uji statistik menunjukkan bahwa ada hubungan antara jaminan dengan kepuasan pasien. Hasil penelitian juga sesuai dengan pendapat Azwar dan Parasuraman yang menyatakan bahwa penilaian jasa pelayanan kesehatan lebih terkait pada ketanggapan petugas memenuhi kebutuhan pasien, kelancaran komunikasi petugas dengan pasien, empati dan keramah tamahan petugas dalam melayani pasien dalam kesembuhan penyakit yang diderita oleh pasien serta kemampuan untuk memberikan pelayanan yang sesuai dengan janji yang ditawarkan.

\section{KESIMPULAN DAN SARAN}

Berdasarkan hasil penelitian yang telah dilakukan dapat disimpulkan bahwa ada hubungan yang signifikan antara mutu 
pelayanan kesehatan berdasarkan indikator penampilan fisik, kehandalan, ketanggapan, jaminan, dan empati dengan kepuasaan pasien dengan masing-masing nilai $p$ value $=0,000$.

Diharapkan kepada Pusat Kesehatan Angkatan Darat (PUSKESAD) POLKES agar lebih memaksimalkan mutu pelayanan kesehatan sehingga kepercayaan pasien dalam memanfaatkan pelayanan kesehatan terus meningkat.

\section{DAFTAR PUSTAKA}

Adam, Arlin, dkk. (2017). Panduan Kerja Penyelesaian Studi Universitas Pejuang RI Makassar, Unit Penelitian dan Pengembangan (UP2), Makassar.

Azwar, Asrul. (1996). Pengantar Administrasi Kesehatan, Binarupa, Aksara.

Daton, Bonifasius, B. (2011). Kualitas Pelayanan Kesehatan Terhadap Kepuasan Pasien Rawat Inap di Rumah Sakit Umum Daerah Larantuka Kabupaten Flores, Skripsi tidak diterbitkan, Makassar, Universitas Veteran RI, Fakultas Kesehatan Masyarakat Universitas Veteran RI.

Eryanto, Henry. (2011). Hubungan Antar Mutu Pelayanan Dengan Kesetiaan Pasien, Econo Sains, Jakarta Vol IX, 107 - 114.

Grace Siama, Juwita. (2017). Hubungan Mutu Pelayan Dengan Kepuasan Pasien Rawat Inap Di Rumah Sakit Umum Daerah Tamaiyang Layang, Jurnal Publikasi Kesehatan Masyarakat Indonesia, Universitas Lambung Mangkurat.

Hatta, Gemala. (2008). Pedoman Manajemen Informasi Kesehatan di Sarana Pelayanan Kesehatan, UI Press, Jakarta hal 37.

Hidayat, A. Aziz, Alimul. (2007). Metode Penelitian Keperawatan dan Teknik Analisis Data, Salemba Medika, Jakarta.
Machmud, Rizanda. (2008). Manajemen Mutu Pelayanan Kesehatan, Jurnal Kesehatan Masyarakat, Vol II, 186 - 190.

Muhyi, R. Rahman, F. Septiana, D, et, al. (2016). The Influence of apperance pharmacy installation and hospitality officer installation of hospital pharmacy to the interest of re-purchase medicine of outpatientin skin and veneral polyclinic. International Journal of Applied Business and Economic Research (IJABER).

Notoadmojo, Soekidjo. (2007). Kesehatan Masyarakat Ilmu dan Seni, PT Rineka Cipta, Jakarta.

Satori, Djam'an, dkk, 2010, Metodologi Penelitian Kualitatif, CV Alfabeta, Bandung.

Sukesi, Retno, Rini. (2012). Profil Kesehatan Provinsi Kalimantan Timur, Dinas Kesehatan RI, Samarinda.

Suyanto. (2011). Metodologi dan Aplikasi Penelitian Keperawatan, Nuha Medika, Yogyakarta.

Tokalese, dkk. (2015). Analisis Kepuasan Pasien terhadap Persepsi Mutu Pelayanan Kebidanan Di Instalasi Rawat Inap Di RSUP Prof. Dr. R. D. Kandou Manado. Artikel Penelitian. Fakultas Kedokteran Universitas Sam Ratulangi Manado.

Tjiptono, Fandi. (2001). Prinsip - prinsip Total Quality Service (TQS), Yogyakarta.

Undang-Undang RI Nomor 44 Tahun (2009), Rumah Sakit, Presiden Republik Indonesia, Jakarta.

Vania. S P. Lahindan, dkk. (2017), Hubungan Kualitas Jasa Pelayanan Tenaga Kesehatan Dengan Tingkat Kepuasan Pasien Pada Ruang Rawat Inap Di Rumah Sakit Ibu dan Anak (RSIA) Kasih Ibu Manado, Fakultas Kesehatan Masyarakat, Universitas Sam Ratulangi. 